\title{
O PLANEJAMENTO DAS AULAS NA TRANSIÇÃO DO ENSINO PRESENCIAL PARA O ENSINO REMOTO: APLICAÇÃO DO PDCA+L
}

\author{
Lucas Ambrósio Bezerra de Oliveira-lucasambro@ufersa.edu.br \\ Universidade Federal Rural do Semiárido - UFERSA. CMA, DENGE \\ Rua Gamaliel Martins Bezerra, 587. Alto da Alegria \\ 59515000 - Angicos, RN-Brasil
}

\begin{abstract}
Resumo: o objetivo deste artigo é relatar a experiência de ensino remoto, no que diz respeito ao seu processo de planejamento, em uma disciplina de engenharia da qualidade. Além disso, busca mostrar como a área da qualidade pode auxiliar na formação do perfil e das competências dos(as) futuros(as) engenheiros(as). Para tanto, foi estruturado um ciclo $P D C A+L$ para auxiliar as atividades de ensino-aprendizagem. Um questionário de autoavaliação foi aplicado para mensurar o domínio e o perfil e competência dos(as) discentes, de acordo com os indicados pelas diretrizes curriculares de engenharia. Os resultados indicam que, com base no ciclo proposto, foi possível atender 100\% das expectativas da turma, sugerindo a boa adequação do ciclo para a transição e planejamento de uma disciplina remota.
\end{abstract}

Palavras-chave: Ensino remoto. Engenharia da qualidade. PCDA. PDCA+L.

\section{INTRODUÇÃO}

A pandemia do COVID-19 acarretou várias implicações para o ensino superior, dentre as quais destaca-se a suspensão das aulas presenciais e, em segundo momento, compeliu às aulas remotas em semestre suplementar e/ou semestre regular (BRASIL, 2020; MELO, 2020; UOL, 2020). Este novo cenário incrementa os desafios na formação de engenheiros em conformidade com o perfil, conhecimentos e habilidades preconizadas pelas novas Diretrizes Curriculares Nacionais (DCNs) dos cursos de graduação em Engenharias (BRASIL, 2019). Diante disso, docentes se foram e são desafiados a (1) fazer a transição do ensino presencial para o ensino remoto (AZEVEDO, 2020) e (2) a prover as ações necessárias para auxiliar na construção do perfil e competências dos engenheirandos(as) (MELLO; ARAÚJO, 2019).

A prática docente guia para experiências somativas, formativas e cumulativas ao longo dos anos e, certamente, auxiliam no processo de transição da atividade de ensino presencial para o remoto. Mas, o novo contexto de ensino remoto mostra e exige novos conhecimentos, habilidades e atitudes acadêmicas para o ensino, tais como, o próprio processo de planejamento (que precisa ser ainda mais profundo), utilização de ferramentas relacionadas às tecnologias de comunicação e informação (TICs), indicação de materiais de suporte ao processo de ensino aprendizagem dos(as) discentes (geralmente virtuais) e atividades e ações de ensinoaprendizagem on-line (OLIVEIRA; LISBÔA; SANTIAGO, 2020). Ou seja, o ambiente on-line exige competências que, apesar de possíveis incorporações, alguns docentes não dominam ou não haviam experimentado até então.

No que tange à formação dos(as) futuros(as) engenheiros(as), as novas DCNs recomendam, no Capítulo II, Art. $3^{\circ}$, que o(a) profissional de engenharia deve ter visão holística, humanista, criativo, deve inovar, resolver problemas, considerar aspectos globais, dentre outras. Além disso, no Art. $4^{\circ}$ o documento recomenda que tenham competências como: "formular e conceber 
soluções desejáveis de engenharia, analisando e compreendendo os usuários dessas soluções e seu contexto", "aplicar conceitos de gestão para planejar, supervisionar, elaborar e coordenar projetos e serviços de Engenharia”, dentre outros (BRASIL, 2019, p. 2).

Neste contexto, de perfil e competências, percebe-se um forte alinhamento com premissas, princípios, filosofias e métodos abordadas na área da qualidade. Paladine (2019) evidencia que a qualidade possui definições de senso comum, que qualquer pessoa consegue definir um produto ou serviço de qualidade. Para além disso e com foco na "ciência" em envolvem a área da qualidade, Garvin (1992), em estudo clássico, evidencia cinco abordagens da qualidade que trazem consigo várias definições, dentre as quais destacam-se: qualidade é conformidade, qualidade é excelência, qualidade é valor percebido, qualidade é durabilidade. E tais abordagens e outras inúmeras definições convergem, por exemplo, para dois elementos basilares da qualidade: o ciclo PDCA e a filosofia kaizen.

Apesar de não serem a mesma coisa, o ciclo PDCA e o kaizen se complementam, pois buscam estimular o aprimoramento e o desenvolvimento tanto de bens, serviços e os processos que os criam, como o fator humano das organizações. A partir de diversas obras e artigos (POMPERMAYER JUNIOR; LIMA; STOCO, 2020; TOLEDO et al., 2017)), por exemplo, pode-se depreender que tais elementos são capazes de prover o aprimoramento do perfil e competências dos trabalhadores e, portanto, podem auxiliar na formação dos(as) engenheirandos(as).

Destarte, diante dos desafios referentes a transição "ensino presencial para o ensino remoto" e o desafio de formar engenheiros(as) no ensino remoto, este trabalho tem como objetivo relatar a experiência de ensino remoto, no que concerne seu processo de planejamento, em uma turma de engenharia da qualidade e, além disso, buscará evidenciar como a área da qualidade pode auxiliar na formação do perfil e competências para os(as) futuros(as) engenheiros(as).

Este artigo se justifica, pela necessidade de compartilhar experiências no tocante à formação de engenheiros(as) para o futuro, que compreendam os efeitos da tomada de decisão para a organização, sociedade e meio ambiente e que estejam alinhados com o perfil e competências estabelecidas pela DCNs 2019. Além disso, este artigo mostra-se relevante por descrever uma experiência de ensino de uma disciplina de forma remota, assistida por tecnologias da informação e comunicação (TICs), devido ao contexto de isolamento social e impossibilidade de aulas presenciais.

Este artigo está estruturado em cinco seções: introdução; seção dois, onde é feita contextualização do ensino na área da qualidade e dos impactos da pandemia no ensino; seção três, que descreve o ciclo proposto; a seção quatro apresenta os resultados disciplina e do perfil e competências da turma; na quinta seção consta as conclusões.

\section{O ENSINO NA ÁREA DA QUALIDADE E A PANDEMIA}

\subsection{Disciplinas para a área da qualidade e contribuição à formação do(a) engenheirando(a)}

O ensino de engenharia da qualidade no Brasil é realizado sob algumas perspectivas. Dentre eles, destaca-se a da Associação Brasileira de Engenharia de Produção (ABEPRO, 2020). Em tal documento, consta que a área da Engenharia da Qualidade é subdivida em quatro setores: controle estatístico, controle metrológico, normalização e certificação de qualidade, confiabilidade. Além destes, há as cinco subáreas da engenharia da qualidade da ABEPRO: 


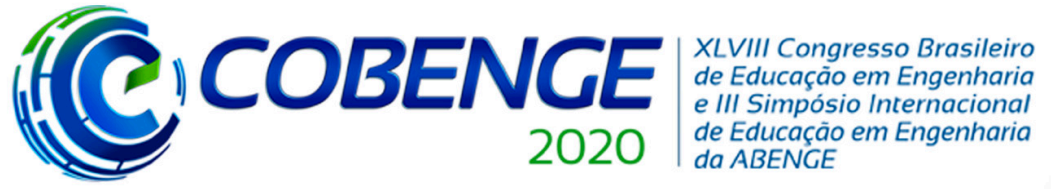

"Os desafios para formar hoje o engenheiro do amanhã"

gestão de sistemas da qualidade, planejamento e controle da qualidade, normalização, auditoria e certificação para a qualidade, organização metrológica da qualidade e confiabilidade de processos e produtos.

$\mathrm{Na}$ área de Engenharia de Produção, em geral, esses conteúdos podem ser ministrados em duas ou três disciplinas: o número específico depende da ênfase de cada curso de graduação. Em outras engenharias, de acordo com o foco, o conteúdo das disciplinas pode enfatizar normas técnicas (como na Engenharia Civil), controle estatístico (como na Engenharia Química) ou na metrologia (como na Engenharia Mecânica).

Em alguns cursos de graduação, a disciplina base da qualidade contempla, principalmente, temas relacionados à gestão de sistemas da qualidade, ferramentas básicas da qualidade, normalização, auditoria e certificação da a qualidade. Para estes casos, tem-se disciplinas com 60 horas-aula, que podem ser divididas em teóricas e práticas, que podem ser chamadas de Gestão da Qualidade, Sistemas de Gestão da Qualidade, Engenharia da Qualidade (I, II ou III), Controle Estatístico da Qualidade, dentre outras variações em torno destas (UFERSA, 2020; UFRGS, 2020).

Em geral, há disciplinas que focam no aspecto de gestão e outras na área da engenharia. Ao tratar da gestão, autores desdobram conteúdos como a evolução da qualidade, definições, princípios, ferramentas, sistemas de gestão da qualidade. Neste contexto, a melhoria contínua pode ser "implementada" e buscada por meio de algumas abordagens como o ciclo PDCA (Plan-Do-Check-Act) e o Kaizen, que apesar de serem diferentes, se contemplam. Estes dois elementos estão intrinsecamente relacionados a ideia de melhoria contínua, que trata de fazer algo e obter resultados, sistematicamente melhor.

O ciclo PDCA é um método que busca racionalizar as etapas e ações, em busca de melhoria contínua, em quatro etapas: plan/planejamento, do/execução, check/verificar e act/agir corretivamente; o kaizen, por sua vez, é uma filosofia japonesa que estimula a mudança para melhor, sejam elas pequenas melhorias ou grande inovações (TOLEDO et al., 2017). Tanto o PDCA como o Kaizen pode ser aplicado e desdobrado em diversas ações e formas complementares e por isso são amplamente abordadas nos temas que envolvem as disciplinas da área da qualidade e, associados a outros temas, como princípios da qualidade, podem auxiliar no alcance do perfil e competências recomendados pela DCN de engenharias, como a visão holística, resolução de problemas e melhoria contínua.

\subsection{Um breve contexto sobre a pandemia e efeitos nas atividades de ensino}

Dentre os impactos que a pandemia provocou em todo mundo, observou-se a suspensão das aulas presenciais. Em muitos casos, as aulas presenciais foram "transformadas" em aulas remotas. Hodges et al. (2020) e Oliveira, Lisbôa e Santiago (2020) evidenciam que o ensino remoto é vista como alternativa diante dos efeitos da pandemia e é caracterizado pela utilização de tecnologias da informação e comunicação (TICs) para ministrar conteúdos que antes eram presenciais e agora é feito de forma, prioritariamente, on-line.

Conforme os autores, a desafio foi que muitos docentes não estavam preparados para essa forma de atuação de ensino, demandando a adaptação da facilitação do conteúdo para o modo remoto. Com isso, percebeu-se, em primeiro momento, pânico e choque em ter que sair de um modelo de ensino no qual a maioria estava habituado. Logo em seguida, observou-se o momento de perspectiva, ou seja, passar a racionalizar "como" fazer a transição do presencial para o remoto. Logo em seguida, observou-se a fase do planejamento, ou seja, de colocar a mão da massa e organizar a nova disciplina. 


\section{UM CICLO PARA AUXILIAR NA TRANSIÇÃO "PRESENCIAL-REMOTO"}

No contexto do ensino remoto, o(a) docente tem sua carga de trabalho maximizada pois todas atividades de ensino devem passar por uma adaptação para o formato que será utilizado (on-line) e por ter que aprender e implementar, simultaneamente, tais atividades (HODGES et al., 2020; OLIVEIRA; LISBÔA; SANTIAGO, 2020). Assim, estes profissionais passaram a buscar de modelo de apoio à transição do ensino presencial para o ensino remoto, um algumas abordagens foram percebidas e dentre elas, destacou-se uma realizada pelo professor Evandro Ribeiro (ABED, 2020) que, propõe seis ações para o processo de adequação para a realidade remoto: entender (fase de diagnóstico), planejar, curar (trata da curadoria em torno do material de apoio ao ensino), comunicar, implementar e avaliar. Assim, percebe-se estas etapas podem ser relacionadas com o ciclo PDCA, resultando em uma perspectiva mais ampla para auxiliar na transição "presencial-remoto".

O ciclo PDCA é um importante método aplicado nas fases que vão desde o planejamento até a correção ou melhoria de alguma ação. Cada letra tem um significado e traz uma série de atos: P (do inglês Plan) - planejar, D (do inglês Do) - executar, C (do inglês Check) - verificar, e A (do inglês $A c t$ ) - agir corretivamente. No Brasil, a Fundação Nacional da Qualidade (FNQ, 2020) estimula a utilização do ciclo PDCL, ou seja, com a fase de aprender (do inglês Learning). Com a utilização do PDCL as organizações podem "aprender" com as ações do PDCA e, com isso, estimular novas aprendizagens.

Figura 1 - Ciclo PDCA $+\mathrm{L}$ para atividades de ensino

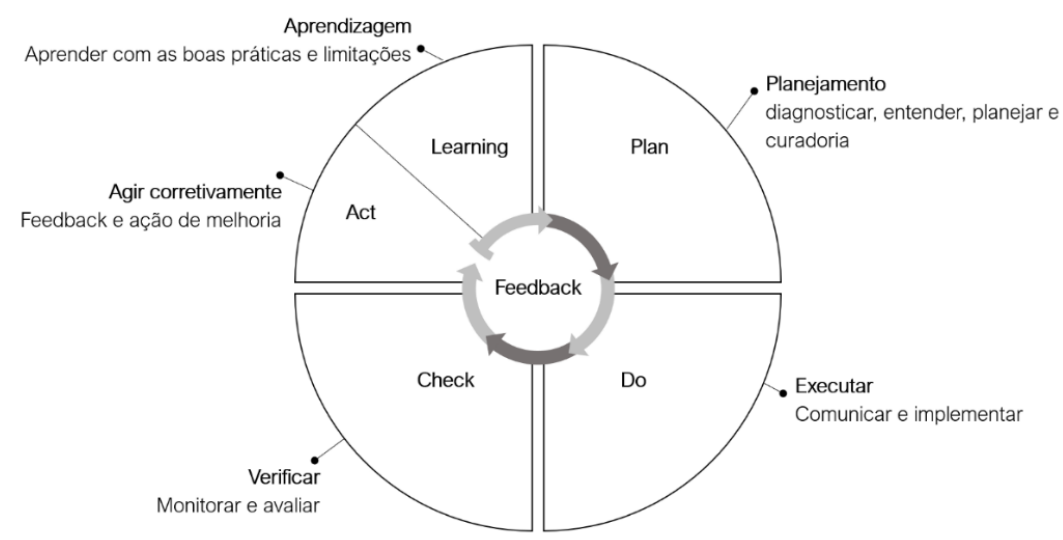

Fonte: Autor (2020) baseado em ABED (2020) e FNQ (2020)

Percebe-se, portanto, que o ciclo PDCA e o PDCL podem ser integrados. Por isso, na proposta deste artigo buscou-se utilizar o ciclo PDCA $+\mathrm{L}$, ou seja, um ciclo que busca planejar, executar, verificar, agir corretivamente/melhorar e aprender.

\subsection{Planejamento (Plan)}

A fase do planejamento para a transição "presencial-remoto" foi dividida em quatro ações: diagnosticar, entender, planejar e curadoria. A primeira ação buscou-se realizar um diagnóstico da situação: qual objetivo da disciplina, quais conhecimentos, habilidade e atitudes deveriam ser estimulados, qual o perfil do engenheiro da qualidade. Em seguida, buscou-se entender o perfil do discente, quais recursos TICs estavam disponíveis para a turma. $\mathrm{Na}$ fase de planejamento houve a conversão das informações e dados obtidos para estrutura o plano de 
ensino da disciplina, tendo atenção a fatores como: acervo bibliográfico disponível virtualmente, sobrecarga cognitiva, atividades que poderiam ser gatilhos para evasão ou baixa participação da turma, quais estratégias de metodologias ativas seriam utilizadas, a dinâmica das aulas e encontros. Em paralelo à fase de planejamento, a ação de curadoria constou da seleção de materiais de apoio ao ensino que seriam disponibilizados para a turma: livros virtuais, vídeos, estudos de caso, leituras complementares, filmes e documentários relacionados aos temas abordados.

\subsection{Execução (Do)}

A fase de execução do planejamento foi feita em duas ações. A primeira ação foi a de "comunicação". Quiçá, o ponto crítico de sucesso para o bom andamento das aulas, pois cada discente passava a ser responsável pela sua programação de estudo e, para tanto, cabe ao(a) docente comunicar, de forma clara, a dinâmica da disciplina: programação das aulas, conteúdos, referências, atividades, datas das avaliações, prazos, consequências por "quebra de alguma regra" da disciplina.

Portanto, documentos tradicionais, como Plano de Ensino, devem ser ainda mais detalhados para a turma seja capaz de conhecer as exigências e se preparar para elas. Além disso, o(a) docente deve ter interação maior e constante. A segunda ação desta etapa de execução foi a "implementação". Para tanto, deve-se ter clara todas as informações anteriormente pensadas, como o perfil, as competências exigidas (...) e, com base nisso, executar todo o planejamento feito. Além disso, é importante ter um registro claro, firme e preciso em relação à presença nas aulas: seja ela tradicional ou aquela contabilizada a partir da entrega de atividades propostas.

\subsection{Verificar (Check)}

Nesta fase de verificar recorre-se à comunicação e interação, para fazer o acompanhamento e o monitoramento diário e sistemático das atividades de ensino. A partir deste feedback constante, o(a) docente deve ajustar uma determinada ação, conforme a necessidade, e comunicar as mudanças à turma. Além disso, tem-se ainda a atividade de avaliação, seja formativa ou somativa.

\subsection{Agir e Aprender (Act e learning)}

Com base em todas as ações executadas e nos feedbacks coletados, o(a) docente tem a possibilidade de ajustar as ações e, com base nessas experiências, aprender com as boas práticas e com as limitações observadas. Por isso, o processo de feedback é contínuo e permeia todo o processo do ciclo, trazendo as ações de correção e aprendizado para essa etapa do ciclo.

\section{RESULTADOS}

\subsection{A disciplina no ensino remoto}

O processo de aplicação do ciclo $\mathrm{PDCA}+\mathrm{L}$ e suas sub etapas permitiram um planejamento específico para o contexto remoto, resultando em três principais resultados: plano de ensino específico para o ensino remoto; guia de estudos e atividades; atividades pedagógicas virtuais.

$\mathrm{Na}$ etapa do planejamento (diagnosticar, entender, planejar e curar) foi possível compreender e conhecer o perfil da turma. Com base nessas informações básicas foi possível 


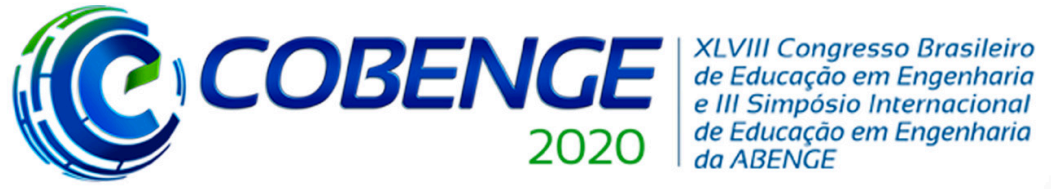

"Os desafios para formar hoje o engenheiro do amanhã"

estabelecer o planejamento da disciplina, que resultou em dois documentos norteadores: plano de ensino específico para o ensino remoto e o guia de estudos e atividades.

O plano de ensino, além dos elementos tradicionais (ementa, objetivos, conteúdo programático, processo de avaliação) teve seções específicas para o contexto remoto, tais como metodologia, atividades síncronas e assíncronas, registro de presença e atividades. A metodologia, apesar de ser um elemento tradicional, foi totalmente redesenhada para a modalidade remota. Em função disso, houve a necessidade de estruturar o guia de estudos e atividades, um documento que consta toda a programação das aulas, tópicos, referências (todas virtuais) e a relação de atividades que deveriam ser cumpridas. Além disso, o guia de estudos e atividades continha o detalhamento de como seria a aula (síncrona ou assíncrona, forma de contabilizar a presença e prazos de entrega das atividades da aula). Resultado da atividade de curadoria, foi possível indicar acervo virtual, oferecido pela biblioteca virtual da Universidade, bem como vídeo e estudos de caso totalmente on-line.

$\mathrm{Na}$ fase de execução foi feita toda a comunicação do planejamento da disciplina para a turma, evidenciando cada etapa do semestre, atividades que deveriam ser cumpridas, como os(as) discentes poderiam acessar o material virtual, dentre outros informes. Essa atividade foi essencial para alinhar os objetivos do docente com as expectativas dos(as) discentes e, assim, maximizar os resultados das disciplinas. Ainda na etapa de comunicação, semanalmente o docente revisa e informava os principais "compromissos" de cada semana de aula. Após a comunicação, foi feita a implementação, ou seja, o início do componente curricular. Nesta etapa, a maior parte das aulas foram síncronas, ou seja, aulas "ao-vivo", por meio de uma plataforma de vídeo conferência, entre o docente e a turma. $\mathrm{O}$ cômputo das presenças nas aulas era feito a partir das aulas assistidas e do envio das questões de ensino associada a cada aula de conteúdo. Desta forma, mesmo quando não era possível, por qualquer motivo, assistir aula no horário previsto, o(a) discente poderia repor a aula sem qualquer prejuízo.

As atividades pedagógicas virtuais consistiram em um conjunto de atividades com objetivo de auxiliar a turma na internalização do conteúdo e atividades práticas. Assim, foi possível realizar jogos educativos com temas: "quem sou eu: gurus da qualidade"; quizzes sobre os mais diversos temas; estudos de caso, mesclando texto base e pesquisa "real" sobre o caso em análise; seminários sobre temas hodiernos da disciplina, como a engenharia da qualidade $4.0 \mathrm{e}$ competências do engenheiro da qualidade; pesquisa virtual sobre expectativas e percepções sobre a qualidade de serviços no contexto da pandemia.

Uma outra atividade pedagógica que trouxe resultados acima da média, foram publicações realizadas em perfil de Instagram. A turma criou um perfil, privado, e cada discente, após a aula, fazia um relato sobre os temas contemplados: poderia ser um relato pessoal; um relato teórico, explicando e aprofundando o assunto; ou algum relato prático. Apesar de exigir muito da turma, já que toda aula resultava em uma postagem, o resultado foi positivo para turma (pois tinha um espaço para refletir e registrar) e para o docente (pois foi possível acompanhar a percepção e o aprendizado de cada discente). Por ser uma ferramenta do cotidiano da turma, foram excelentes as postagens.

A fase de verificação e avaliação constava de feedbacks contínuos, tanto por parte da turma, quanto por parte do docente. A avaliação foi, primordialmente, formativa, ou seja, valorizava e acompanhava o progresso da turma ao longo das aulas e não, necessariamente, apenas em uma avaliação somativa. Fruto disso é que a avaliação somativa era a atividade que tinha o menor peso para atribuir a nota/conceito do(a) discente.

$\mathrm{Na}$ fase de agir corretivamente e aprender as principais ações eram de ajustes na dinâmica das aulas: fazer intervalos curtos a cada 50 minutos de aula, para reduzir a fadiga e maximizar 
(C) COBENCE

"Os desafios para formar hoje o engenheiro do amanhã"

a possibilidade de concentração nas aulas; dispor as atividades a serem cumpridas no início da semana (ao invés de fazer a cada aula); e maximizar o número de atividades em grupo.

A estruturação e aplicação do ciclo PDCA $+\mathrm{L}$ permitiu um bom planejamento, resultados e feedbacks positivos da turma. Em pesquisa feita após a conclusão do semestre (dados apresentados na Figura 2), 73,7\% da turma apontou que a carga horária da disciplina foi suficiente, $89,9 \%$ apontou suficiência da carga teórica; $77,8 \%$ apontou que carga prática foi satisfatória. Em relação às atividades pedagógicas, $91,1 \%$ evidenciou que a postagem no Instagram foi a melhor, seguida de $16,7 \%$ que foram os jogos educativos; e $61,1 \%$ apontou que a quantidade das atividades foi suficiente. Neste caso, cabe uma reflexão sobre a carga de atividades, que pode ser melhor gerenciada e comunicada à turma, apesar da turma julgarem o nível de dificuldade delas como sendo equilibrado.

Por fim, $77,8 \%$ da turma disse que a disciplina superou as expectativas e atendeu $22 \%$ dos(as) discentes. O feedback qualitativo aponta uma indicação do motivo de apenas $50 \%$ da turma apontar que se matricularia em uma disciplina com metodologia similar: a intensidade do semestre. A disciplina em análise foi ofertada como uma disciplina de férias, assim, foram 6 semanas de aulas diárias o que, apesar o planejamento, deixa o semestre mais pesado e cansativo que o normal.

Figura 2 - Gráficos resultados da avaliação da disciplina remota

A

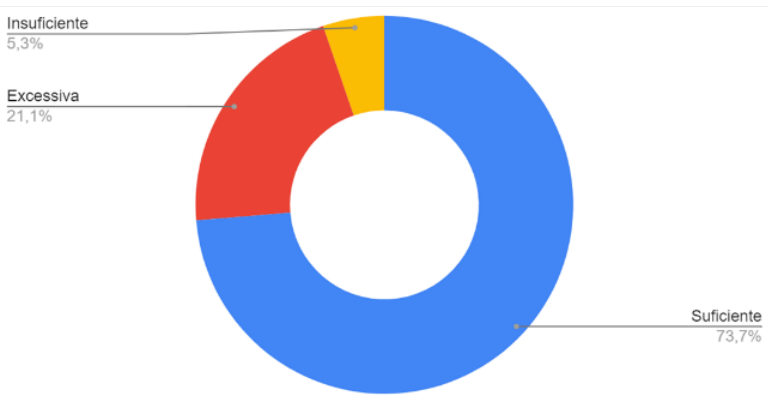

$\mathrm{C}$

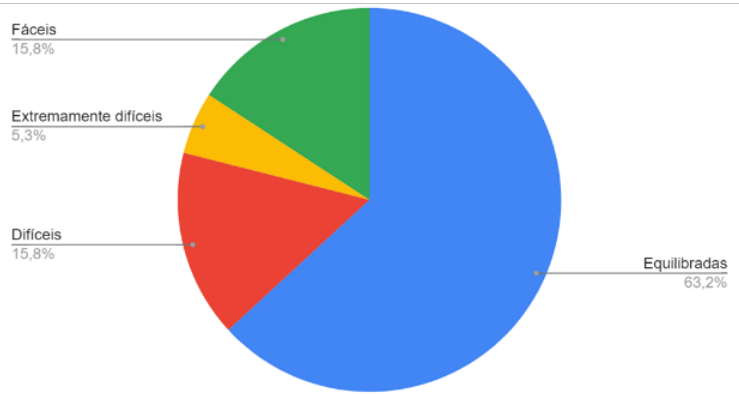

$\mathrm{B}$

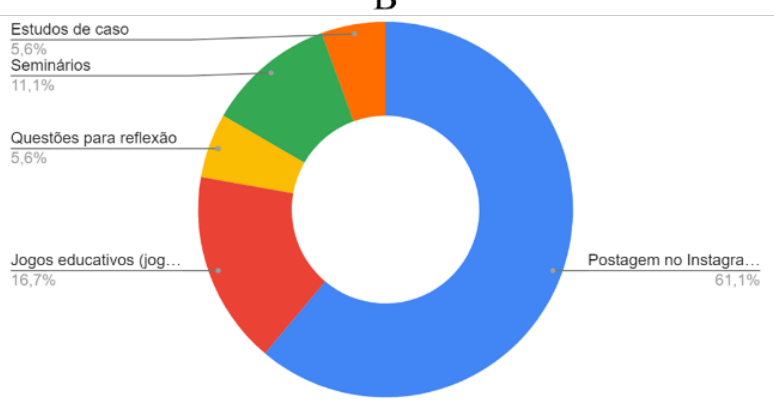

$\mathrm{D}$

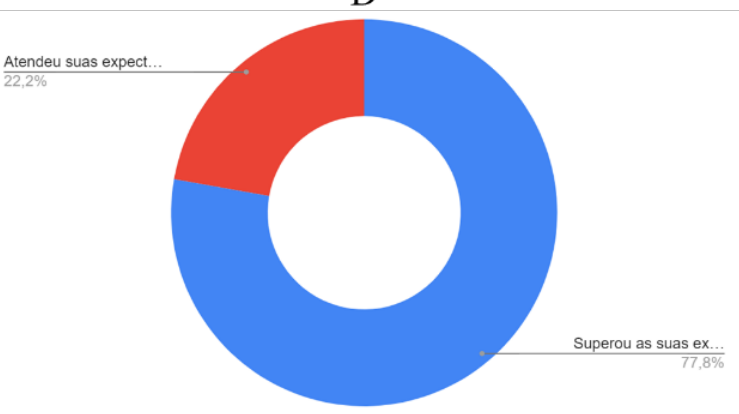

Fonte: Dados da pesquisa (2020)

Legenda: Gráfico A - feedback sobre carga horária; Gráfico B - Qual a melhor atividade para processo de aprendizagem?; Gráfico C - Feedback sobre o nível de dificuldade das atividades; Gráfico D - Feedback sobre expectativas.

\subsection{O perfil e competências no ensino remoto}

Como destacado, as disciplinas na área de qualidade, principalmente as que compreendem a "gestão da qualidade", tratam de princípios, abordagens relacionadas à melhoria contínua, identificação, análise e resolução de problemas, filosofias como a do kaizen, dentre outros, e tais temas têm uma grande ênfase no lado humano das organizações e têm forte sinergia com o perfil e competências esperados para os engenheiros. Assim, buscou-se identificar como a 
turma fez auto avaliação, após a disciplina, em relação a formação do perfil profissional deles, cujo resultado é ilustrado na Figura 03.

Figura 03 - Avaliação do perfil e competências pós disciplina remota

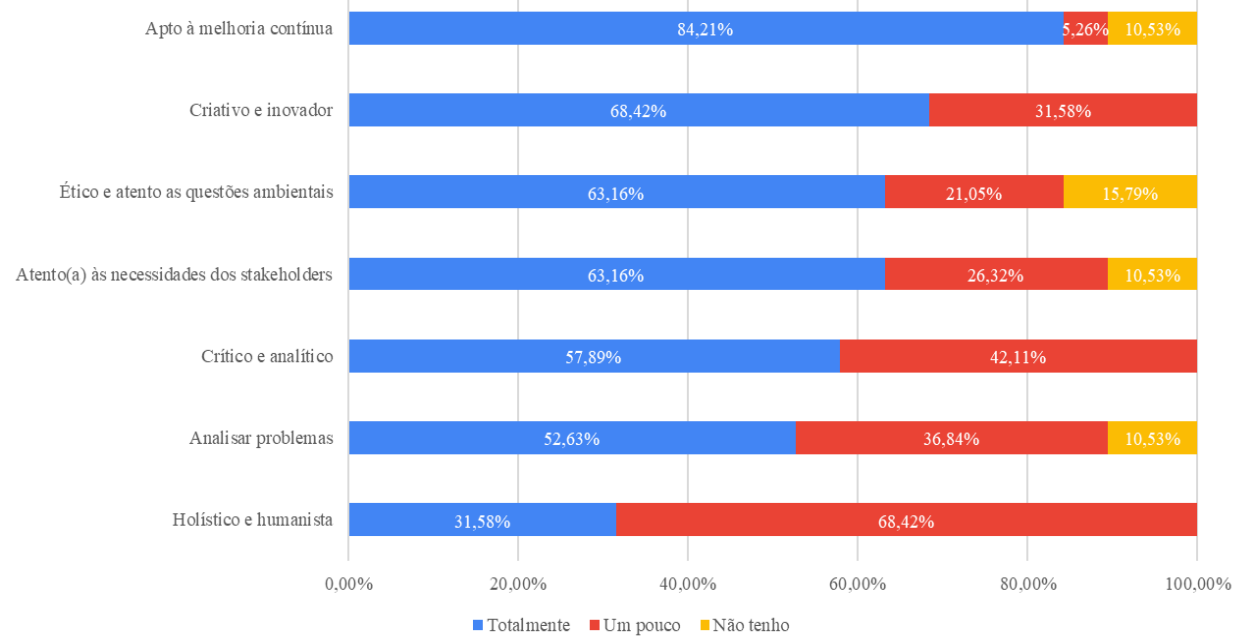

Fonte: Dados da pesquisa (2020)

Percebe-se que a turma se considera totalmente apta à melhoria contínua, seguido de criativo e inovador. Em relação as questões éticas e atento as questões ambientais, $15,76 \%$ da turma não sentem que têm essas competências. $O$ fato de ser uma turma não ter contato com disciplinas da área ambiental pode explicar esse percentual. Outro ponto a se destacar é o perfil "holístico e humanista": apesar da maioria ainda se considerar pouco apto, acredita-se que tais características podem ser desenvolvidas em outras disciplinas e aprimoradas com o amadurecimento acadêmico, pessoal e profissional do(as) discentes.

\section{CONCLUSÕES}

Este trabalho buscou descrever uma experiência no ensino remoto, evidenciando o processo de planejamento até a execução das atividades. Por meio de tais atividades, corroborou com a formação do perfil e competências dos(as) futuros(as) engenheiros, tendo em vista o ensino da qualidade (enquanto área de conhecimento).

A estruturação e aplicação do ciclo PDCA+L permitiu um bom planejamento, resultados e feedbacks positivos da turma. Em função disso, $100 \%$ das expectativas da turma foram atendidas, sendo que para $77,8 \%$ dos(as) discentes, as expectativas foram superadas.

E, em relação as contribuições da disciplina para formação do engenheiro, percebeu-se que, a partir da ênfase da disciplina (que foi na gestão da qualidade), 84,21\% da turma se sente apto à melhoria contínua e $68,42 \%$ consideram-se totalmente criativos e inovadores. Por ser uma disciplina de início de curso, espera-se que os(as) discentes evoluam no aprimoramento do perfil e competências. Destarte, é importante a continuidade e realização de estudos que envolvam o desenvolvimento do perfil e competências no contexto de ensino remoto. 


\section{REFERÊNCIAS}

ABED. Associação Brasileira de Educação à Distância. EAD durante a pandemia. Direção: Associação Brasileira de Educação à Distância ABED. [S. l.: s. n.] (1:35:30). Disponível em: https://www.youtube.com/watch? $\mathrm{v}=$ FavvaXU7GvQ\&feature $=$ youtu.be $\& \mathrm{t}=1275$. Acesso em: 5 ago. 2020.

ABEPRO. ABEPRO - Associação Brasileira de Engenharia de Produção | A Profissão. [s. l.], 2020. Disponível em: http://portal.abepro.org.br/a-profissao/. Acesso em: 7 ago. 2020.

AZEVEDO, Margarida. Universidades federais planejam aulas online após 4 meses.

Universidades federais planejam aulas online após 4 meses, [s. l.], 19 jul. 2020 Disponível em: https://jc.ne10.uol.com.br/colunas/enem-e-educacao/2020/07/11955443-universidadesfederais-planejam-aulas-online-apos-4-meses.html. Acesso em: 7 ago. 2020.

BRASIL, Ministério da Educação. Corona Vírus - Monitoramento nas Instituições de Ensino. [s. l.], 2020. Disponível em: http://portal.mec.gov.br/coronavirus/. Acesso em: 7 ago. 2020.

BRASIL, Ministério da Educação. Conselho Nacional de Educação. Câmara de Educação Superior. Resolução CNE/CES No 2, de 24 de abril de 2019. Institui as Diretrizes Curriculares Nacionais do Curso de Graduação em Engenharia. 24 abr. 2019. Disponível em: http://portal.abepro.org.br/wp-content/uploads/2020/05/RESOLU\%C3\%87\%C3\%83ON\%C2\%BA-2-DE-24-DE-ABRIL-DE-2019-RESOLU\%C3\%87\%C3\%83O-N\%C2\%BA-2DE-24-DE-ABRIL-DE-2019-DOU-Imprensa-Nacional.pdf. Acesso em: 5 ago. 2020.

FNQ, Fundação Nacional da Qualidade. Sobre o MEG - Modelo de Excelência da Gestão. [s. l.], 2020. Disponível em: https://fnq.org.br/sobre-o-meg/. Acesso em: 5 ago. 2020.

GARVIN, David A. Gerenciando a qualidade: a visão estratégica e competitiva. Rio de Janeiro: Qualitymark, 1992. E-book.

HODGES, Charles et al. As diferenças entre o aprendizado online e o ensino remoto de emergência. Revista da Escola, Professor, Educação e Tecnologia, [S. l.], v. 2, 2020. Disponível em: http://escribo.com/revista/index.php/escola/article/view/17. Acesso em: 7 ago. 2020.

MELLO, Luciana Torres Correia de; ARAÚJO, Richardson B. C. As capacidades dinâmicas e operacionais para o ensino de engenharia no ambiente universitário. In: CONGRESSO BRASILEIRO DE EDUCAÇÃO EM ENGENHARIA - COBENGE 2019, Fortaleza/CE. Anais do XLVII Congresso Brasileiro de Educação em Engenharia - COBENGE. Fortaleza/CE: [s. n.], 2019. p. 1-9. Disponível em: http://www.abenge.org.br/sis_artigos.php. Acesso em: 5 ago. 2020.

MELO, Karine. MEC autoriza aulas online no ensino superior até dezembro. MEC autoriza aulas online no ensino superior até dezembro, Brasília, 17 jun. 2020 Disponível em: https://agenciabrasil.ebc.com.br/educacao/noticia/2020-06/mec-autoriza-aulas-line-no-ensinosuperior-ate-dezembro. Acesso em: 7 ago. 2020. 
OLIVEIRA, Maria Auxiliadora Monteiro; LISBÔA, Eliene Soares dos Santos; SANTIAGO, Nilza Bernardes. PANDEMIA DO CORONAVÍRUS E SEUS IMPACTOS NA ÁREA EDUCACIONAL. Pedagogia em Ação, [S. l.], v. 13, n. 1, p. 17-24, 2020.

PALADINI, Edson Pacheco. Gestão e avaliação da qualidade: uma abordagem estratégica. São Paulo: Atlas, 2019. E-book.

POMPERMAYER JUNIOR, Marcelo; LIMA, André de; STOCO, Wanderson Henrique. Busca de Melhoria Contínua em Processo Produtivo: Aplicações das Ferramentas de Gestão da Qualidade / Search for Continuous Improvement in Productive Process: Applications of Quality Management Tools. Brazilian Journal of Development, [S. l.], v. 6, n. 3, p. 1062110634, 2020. Disponível em: https://doi.org/10.34117/bjdv6n3-078

TOLEDO, José Carlos de et al. Qualidade: gestão e métodos. Rio de Janeiro: LTC, 2017. Ebook.

UFERSA, Campus Angicos. Engenharia de Produção: apresentação do curso. [s. l.], 2020. Disponível em: https://engproducaoangicos.ufersa.edu.br/apresentacao/. Acesso em: 7 ago. 2020.

UFRGS, curso de graduação em Engenharia de Proodução. Engenharia de produção: estrutura curricular do curso. [s. l.], 2020. Pasta. Disponível em:

http://www.ufrgs.br/ufrgs/ensino/graduacao/cursos/exibeCurso?cod_curso=322. Acesso em: 5 ago. 2020.

UOL. UnB suspende semestre letivo por causa da pandemia de coronavírus. UnB suspende semestre letivo por causa da pandemia de coronavírus, São Paulo, 23 mar. 2020

Disponível em: https://educacao.uol.com.br/noticias/2020/03/23/unb-calendario-academicocoronavirus.htm. Acesso em: 7 ago. 2020.

\title{
PDCA + L: THE PLANNING PROCESS FOR "PRESENTIAL-REMOTE" TRANSITION AND THE TRAINING OF SKILLS OF THE ENGINEER IN REMOTE EDUCATION
}

\begin{abstract}
: this paper aims to report the remote teaching experience, with regard to its planning process, in a subjects of quality engineering. Moreover, seeks to show how the area of quality can help in the formation of the profile and skills for the future engineers. Therefore, a PDCA+L cycle was structured to assist teaching-learning activities. A self-assessment questionnaire was applied to measure the domain and the profile and competence of the students according to those indicated by the engineering curriculum guidelines. The results indicate that, based on the proposed cycle, it was possible to meet $100 \%$ of the students' expectations, suggesting the good adequacy of the cycle for the transition and planning of a remote subject.
\end{abstract}

Keywords: Remote education. Quality Engineering. PCDA. PDCA + L. 